\title{
A quantitative approach to the right to education
}

Citation for published version (APA):

Kleine Deters, B. (2021). A quantitative approach to the right to education: concept, measurement, and effects. [Doctoral Thesis, Maastricht University]. Maastricht University. https://doi.org/10.26481/dis.20210628dk

Document status and date:

Published: 01/01/2021

DOI:

$10.26481 /$ dis.20210628dk

Document Version:

Publisher's PDF, also known as Version of record

\section{Please check the document version of this publication:}

- A submitted manuscript is the version of the article upon submission and before peer-review. There can be important differences between the submitted version and the official published version of record.

People interested in the research are advised to contact the author for the final version of the publication, or visit the DOI to the publisher's website.

- The final author version and the galley proof are versions of the publication after peer review.

- The final published version features the final layout of the paper including the volume, issue and page numbers.

Link to publication

\footnotetext{
General rights rights.

- You may freely distribute the URL identifying the publication in the public portal. please follow below link for the End User Agreement:

www.umlib.nl/taverne-license

Take down policy

If you believe that this document breaches copyright please contact us at:

repository@maastrichtuniversity.nl

providing details and we will investigate your claim.
}

Copyright and moral rights for the publications made accessible in the public portal are retained by the authors and/or other copyright owners and it is a condition of accessing publications that users recognise and abide by the legal requirements associated with these

- Users may download and print one copy of any publication from the public portal for the purpose of private study or research.

- You may not further distribute the material or use it for any profit-making activity or commercial gain

If the publication is distributed under the terms of Article $25 \mathrm{fa}$ of the Dutch Copyright Act, indicated by the "Taverne" license above, 


\section{Nederlandse samenvatting}

\section{Hoofdstuk 1 - Introductie}

Sommige zaken zijn makkelijk te meten. Water, bijvoorbeeld, zal in normale omstandigheden altijd koken bij 100 graden Celsius. Alles wat je nodig hebt om dit te meten is een thermometer, een warmtebron, en - voor je eigen veiligheid een stel ovenwanten.

Andere zaken zijn lastiger te meten. Hoewel we waarnemen dat water uitzet als het verwarmd wordt, is het nog niet zo makkelijk om precies te berekenen hoeveel de zeespiegel precies zal stijgen als (indirect) gevolg van klimaatverandering. Het is mogelijk dat de wetenschap er behoorlijk naast zit, zoals opgemerkt door Herman Finkers:

"Volgens de wetenschap stijgt de zeespiegel met tien centimeter per eeuw. Ik heb het voor de aardigheid eens nagemeten... Kwam al op een stijging van anderhalve meter in zes uur."

Hopelijk voelen de meesten van jullie nattigheid bij deze redenering, maar er moet nog heel wat water door de Rijn voordat we de precieze impact van klimaatverandering weten. Helaas is het in het leven zo dat de meeste interessante en belangrijke vragen meer van de categorie klimaatverandering en minder van de categorie kokend water zijn. Eén van zulke vragen gaat over de relatie tussen mensenrechten en ontwikkeling (met ontwikkeling wordt 'ontwikkeling' zoals in ontwikkelingssamenwerking bedoeld). Helaas iets drogere stof dan water, maar daarom niet minder belangrijk.

Op het eerste gezicht lijkt deze relatie niet zo gecompliceerd. Als we elk kind nu eens mensenrechten geven, dan komt die ontwikkeling toch vanzelf? Dat lijkt in elk geval het devies van bijvoorbeeld de Duurzame Ontwikkelingsdoelen en allerlei organisaties zoals UNICEF en Oxfam. Maar wat betekent het nu eigenlijk? Wat is 'ontwikkeling' bijvoorbeeld? Is dat puur economische ontwikkeling? Of is het de dochter van een gierstboer in de Sahel regio, die als eerste van haar familie naar de universiteit kan? En wat houdt het eigenlijk in om iemand mensenrechten te verlenen? Is het al voldoende om het netjes wettelijk te regelen? Of zijn de mensenrechten pas echt geregeld als niemand in onze maatschappij met een lege maag naar bed gaat? En als dat laatste het geval is, hebben we de wet dan eigenlijk wel nodig? 
Het onderwerp van deze dissertatie is de relatie tussen mensenrechten en ontwikkeling, en hoe we dat kunnen meten. De focus ligt op het wettelijk recht op basisonderwijs. Wetten zijn geen nummers, en we hebben dus een methode nodig om ze te kwantificeren (= in cijfers te vatten). Samengevat heeft ons onderzoek drie doelen:

1. Een juridisch kloppende meting van de wetgevende aspecten van mensenrechten;

2. De mogelijkheid om deze meting te gebruiken in een statistisch model om zo de relatie tussen wet en ontwikkeling te testen.

3. Dit te doen op een manier die toegankelijk is voor zowel juristen als sociale wetenschappers.1

Drie zaken vormen de aanleiding voor dit onderzoek. De eerste is de trend binnen ontwikkelingsstudies richting evidence-based interventies. In de praktijk betekent dit een nadruk op kleinere interventies, zoals het ontwormen van schoolkinderen - want het effect daarvan is makkelijk meetbaar. Hierdoor krijgen de grote vragen relatief minder aandacht. De hoop is dat door mensenrechten meetbaar te maken ze een grotere rol kunnen spelen in het ontwikkelingsdenken. De tweede is de observatie dat bestaande initiatieven om mensenrechten te meten juridisch niet zo sterk zijn. Ze focussen op het meten van uitkomsten, zoals bijvoorbeeld het percentage kinderen dat naar school gaat. Maar mensenrechten zijn meer dan uitkomsten; zonder een juridische basis en een nette manier om het te implementeren kun je niet echt spreken van een recht. De laatste aanleiding is dat bestaand onderzoek naar de impact van wettelijke rechten op ontwikkelingsuitkomsten voornamelijk het effect van internationale verdragen meet. De juridische kracht van verdragen is echter matig, aangezien er geen effectieve handhavingsmethoden zijn. Daarnaast zijn de mechanieken die ondertekening van zo'n verdrag 'vertalen' naar uitkomsten heel anders dan de mechanieken van een nationale wet. Het loont dus de moeite om de wet op nationaal niveau te bestuderen.

1 Met'sociale wetenschappers' bedoel ik niet wetenschappers met wie je makkelijk een pintje kan pakken, maar wetenschappers in de 'social sciences', zoals sociologie, ontwikkelingsstudies, of economie. 
We zijn natuurlijk niet de eersten die dit opmerken. Er is een hele tak van literatuur die kritiek uitoefent op de tendens om ontwikkeling in het algemeen (en mensenrechten in het bijzonder) te kwantificeren. De kritiek gaat ruwweg over vier zaken:

1. Epistemologie (kennistheorie, oftewel de filosofische vraag wat kennis is en hoe we het betrouwbaar kunnen vergaren);

2. Welke rechten er wel, en welke er niet worden gemeten;

3. Het creëren van indicatoren (een indicator is een nummer, een indicatie van hetgeen gemeten wordt);

4. Hoe de verschillende indicatoren bij elkaar opgeteld moeten worden om tot een index (of 'eindscore') te komen.

De epistemologiekritiek gaat over de onderliggende aanname dat kwantificatie inherent objectief is. Met andere woorden; meten is weten. Door te meten versimpel je complexe zaken, kun je verschillende landen en tijden met elkaar vergelijken, en heb je genoeg aan een kleine set van technocratische oplossingen voor alle problemen. Omdat cijfers zogenaamd niet liegen, hoef je geen moeilijke politieke discussies aan te gaan. Dit idee klopt misschien voor kokend water, maar objectiviteit betekent heel wat anders in een juridische context.2 Rechters zijn in principe objectief, maar zijn het tegelijkertijd ook voortdurend met elkaar oneens. Deze ruimte voor discussie zie je vaak niet terug in het uiteindelijke instrument: doordat het juridische argument is verworden tot een nummertje krijgt het de zweem van objectieve waarheid.

Wanneer er gekozen moet worden welke rechten wel (en welke niet) worden gemeten, dan is de doorslaggevende factor vaak 'meetbaarheid'. Het vertalen van taaie juridische kost in makkelijk behapbare nummers is een moeilijk en tijdrovend proces, dus in de praktijk zie je dat onderzoekers veel gebruik maken van reeds bestaande data. Maar 'meetbaarheid' zegt ons niets over wat er inherent belangrijk is aan het gemeten recht, en zou dus niet relevant moeten zijn in de keuze van wat we meten.

2 Of elke andere complexe context. 
In dit onderzoek ondervangen we de eerste twee kritiekpunten door uitgebreid te vertellen over de stappen in het proces, de dilemma's die we tegenkomen, en de keuzes die we daarin maken. Hierdoor wordt de vaak verstopte juridische argumentatie weer zichtbaar. Daarnaast proberen we te voorkomen dat meetbaarheid een grote rol speelt door uit te gaan van wat juristen verstaan onder het recht van onderwijs, en daar zelf data bij te verzamelen. Onze omgang met het derde en vierde kritiekpunt komt aan bod in respectievelijk hoofdstuk twee en drie.

Ondanks deze zorgvuldige aanpak is het belangrijk dat we ons beseffen dat de kennis die door meting wordt geproduceerd altijd onvolledig is. Kwantificatie is een vertalingsproces; van juridische taal tot nummers, en van lokale contexten tot vergelijkbare eenheden. In dit proces moeten er tal van keuzes gemaakt worden, en als je kiest voor het ene betekent dat noodzakelijkerwijs dat je wat anders moet laten. Het onontkoombare gevolg hiervan is dat we bepaalde nuances verliezen, en dat er lacunes zullen zitten in het uiteindelijke resultaat.

\section{Hoofdstuk 2 - Het creëren van indicatoren}

Bij het meten van mensenrechten is gebruik gemaakt van het volgende vijfstappenplan:

1. Een analyse van hoe het recht beschreven wordt in het relevante verdrag.

2. Bepalen van het rechtsconcept en de reikwijdte.

3. Identificeren van passende indicatoren die overeenkomen met de verplichtingen van de staat.

4. Bepalen hoe er wordt omgegaan met het principe van 'progressive realisation'.

5. Bepalen wanneer er sprake is van het overtreden van het gemeten recht.

Voor ons begrip van het recht op onderwijs maken we gebruik van het Internationaal Verdrag inzake Economische, Sociale, en Culture Rechten (IVESCR) uit 1966. Het recht op onderwijs zoals hierin beschreven sluit nauw aan bij onder andere de VN Verklaring van de Rechten van de Mens uit 1948 en het Verdrag inzake de Rechten van het Kind uit 1989. Daarnaast is het door bijna alle landen ondertekend, en is het uitgebreid becommentarieerd in de literatuur. 
Er zijn verschillende manieren om het recht op onderwijs te conceptualiseren. Wij hebben gekozen voor de minimum core obligations (MCOs), de minimumkern van verplichtingen. Dit is een lijst van zeven verplichtingen waar staten minimaal aan moeten voldoen op het gebied van onderwijs. De lijst is opgesteld door het VN Comité voor Economische, Sociale, en Culturele Rechten, en kent de volgende verplichtingen:

1. Onderwijs is een recht.

2. Er mag niet gediscrimineerd worden in het recht op toegang tot onderwijs.

3. Basisonderwijs is gratis.

4. Basisonderwijs is verplicht.

5. Ouders/wettelijke voogden hebben het recht een school te kiezen die bij hun kind en overtuigingen past, en er zelf één te beginnen als ze deze niet kunnen vinden.

6. Het land heeft een nationale onderwijsstrategie met als doel universeel, gratis, en verplicht basisonderwijs, uit te voeren in een redelijke tijd.

7. De doelen van het onderwijs voldoen aan internationale mensenrechten.

Er is voor deze lijst gekozen omdat ze rechttoe rechtaan is, een sterke verankering in het verdrag heeft, en grotendeels context-onafhankelijk is. Deze lijst is vervolgens uitgewerkt in 18 verschillende indicatoren, de derde stap in het meetproces. Aan de hand van de indicatorenlijst hebben we vervolgens de onderwijswetgeving in 45 landen in sub-Sahara Afrika, Latijns-Amerika en de Caraiben bestudeerd, tussen 1990 en 2018.3

Een voorbeeld van zo'n indicator is de vraag of het wettelijk toegestaan is onderwijs te geven gebaseerd op een religieuze of filosofische basis. Hier waren drie mogelijke uitkomsten; het is niet toegestaan, het is slechts één religie toegestaan, of het is wel toegestaan. Aan elke uitkomst is een numerieke score verbonden, en hierdoor kunnen we dus het recht op onderwijs meten. In de praktijk bleek dat de meeste indicatoren minder rechttoe rechtaan waren dan we in eerste instantie verwacht hadden. Een aantal landen stond bijvoorbeeld

3 Voor de grappenmakers; nee, dat is niet hoe lang we er over gedaan hebben. 
religieus onderwijs wel toe, maar alleen als er aan allerlei extra voorwaarden was voldaan (zoals bijvoorbeeld toestemming van de minister). Is onderwijs op religieuze basis dan wel toegestaan? Wij hebben besloten dat - als dit soort regels alleen voor scholen op religieuze of filosofische basis gelden - dat dit niet het geval was. Dit soort keuzes zijn goed te verdedigen, maar het is ook voor te stellen dat andere juristen de lat net ergens anders leggen.

De vierde stap in het meten van mensenrechten is bepalen hoe er wordt omgegaan met het principe van 'progressive realisation'. Grosso modo komt dit principe er op neer dat de verplichting van landen om socio-economische mensenrechten te vervullen maar zover gaat als hun capaciteit om dat te doen. Het is simpelweg niet realistisch om te verwachten dat Burkina Faso eenzelfde mate van gezondheidszorg kan realiseren voor haar inwoners als Nederland. Progressive relisation schrijft voor dat als landen zich hebben gecommitteerd aan een bepaald recht (bijvoorbeeld door het tekenen en ratificeren van een verdrag), zij stappen moeten zetten, met het maximum van de hun beschikbare middelen, om uiteindelijk het volledige recht te vervullen. Er is geen overeenstemming in de literatuur over wat dit precies in de praktijk betekent - één van de redenen waarom het zo lastig is socio-economische mensenrechten te meten. In ons onderzoek vermijden we deze discussie door alleen de minimum core obligations te meten: deze vormen de ondergrens van een recht, en het principe van progressive realisation is daardoor niet van toepassing. Anders zouden er immers situaties denkbaar zijn dat landen dermate weinig middelen hebben dat er feitelijk geen enkele bescherming van het recht overblijft. De minimum kern van verplichtingen is dus zo opgesteld dat ieder land ter wereld (dat zich aan het recht gecommitteerd heeft) ze kan én moet implementeren.

De laatste stap in het meten van mensenrechten is het bepalen wanneer er sprake is van een overtreding van het gemeten recht. Normaliter is er sprake van een overtreding als juridisch is vastgesteld dat een land niet voldoet aan een verdragsrechtelijke verplichting (zoals het naleven van een mensenrecht). Hoewel we gebruik maken van juridische argumenten om onze meting te doen, is een meting niet hetzelfde als een juridisch argument, en moeten we dus voorzichtig zijn met dit soort vaststellingen. Aan de andere kant is het lastig voor te stellen dat een land dat bijvoorbeeld niet in de wet heeft opgenomen dat basisonderwijs verplicht is, niet in overtreding is. Als uit de data blijkt dat een land niet aan $z^{\prime} n$ verplichtingen voldoet is er wat ons betreft sprake van een prima facie overtreding. (Prima facie is Latijn voor 'op het eerste gezicht'). Zo'n vaststelling zou dan het startschot moeten zijn van verdere juridische discussie. 
Samenvattend hebben we het recht op onderwijs geconceptualiseerd als zeven minimumkernverplichtingen, die onderverdeeld zijn in 18 indicatoren. Deze zijn vervolgens toegepast op 45 landen, over een periode van 29 jaar. Uiteindelijk levert dit meer dan 23.000 datapunten op. Hoe we deze informatiebom behapbaar maken was de uitdaging van het volgende hoofdstuk.

\section{Hoofdstuk 3 - Het construeren van de Recht op Onderwijs Index}

In het derde hoofdstuk behandelen we drie zaken. Eerst creëren we een index, vervolgens gebruiken we deze index om te onderzoeken hoe het recht op onderwijs zich ontwikkeld heeft van 1990 tot nu, en als laatste kijken we in hoeverre de landen in onze data voldoen aan de minimumkernverplichtingen.

Een index is een getal dat een aantal andere getallen samenvat. Een bekend voorbeeld is de consumentenprijsindex, dat een verzameling van de prijs van goederen en diensten bevat, en onder andere gebruikt wordt om de inflatie te berekenen. Het maken van zo'n index vereist veel keuzes: welke indicatoren neem je wel en niet mee, en hoe verhouden de verschillende indicatoren zich rekenkundig tot elkaar? Een veelgehoorde kritiek is dan ook dat indexen moeilijk vergelijkbare zaken op een hoop gooien (zoals levensverwachting, scholingsjaren, en inkomen), en dan ondoorzichtige en complexe rekenmethodes nodig hebben om ze maar te kunnen vergelijken.

Onze Recht op Onderwijs Index probeert dit beter te doen. Al onze indicatoren zijn gebaseerd op de zeven minimumkernverplichtingen; we vergelijken dus geen appels met peren. Elke indicator is in principe een ja/nee-vraag (is deze verplichting wel of niet in de wet opgenomen?), met soms een tussenoptie. De grootste uitdaging was dat we een aantal minimumkernverplichtingen hadden uitgesplitst in meerdere indicatoren. De oplossing was om de indicatoren zo'n gewicht te geven dat elke minimumkernverplichting even zwaar woog. Het resultaat is te zien in de infographic. Hier zie je bijvoorbeeld dat de minimumkernverplichting dat onderwijs een recht is maar één indicator heeft, die dan ook twee keer zo zwaar meeweegt in de index als een indicator van de derde minimumkernverplichting (dat onderwijs gratis is). Aangezien er zeven minimumkernverplichtingen zijn kan elk land tussen de nul (er is geen enkel aspect van de minimumkernverplichtingen vastgelegd in de wet) en zeven (alle minimumkernverplichtingen zijn in de wet vastgelegd) punten halen. 
Na deze index gebouwd te hebben is de data verkend. De trend is positief: alle indicatoren scoren gemiddeld hoger in 2018 dan dat ze in 1990 deden. De hoogste stijger is de verplichting dat elk land een nationale onderwijsstrategie heeft. In 1990 was dat minder dan 10\% van landen, en in 2018 ruim 70\% (niet allemaal van afdoende kwaliteit, maar toch). De minimumkernverplichting dat onderwijs gratis moet zijn steeg het minst, met name doordat weinig landen 'verborgen' onderwijskosten verbieden (zoals schoollunches, uniformen, of boeken).

Hoewel de algemene trend goed is, zijn er grote verschillen tussen landen. Sommige landen schaven continu aan hun onderwijswetgeving, waardoor hun score elke paar jaar een beetje omhooggaat. Andere landen gooien hun hele onderwijswetgeving in één keer om, en 'springen' dan omhoog qua score. Een laatste groep landen doet wel wat, maar niet vaak genoeg en te weinig per keer om echt een verschil te maken. Slechts twee landen eindigen met een slechtere score dan waarmee ze begonnen: Ethiopië en Equatoriaal-Guinea. Geen enkel land slaagt er echter in om te voldoen aan alle minimumkernverplichtingen.

Dit is een teleurstellende uitkomst. In het vorige hoofdstuk hadden we vastgesteld dat de minimumkernverplichtingen een bodem vormen onder de mensenrechten, en dat daaronder eigenlijk geen sprake meer is van een recht op onderwijs. Onze data suggereert dus dat alle landen het recht op onderwijs overtreden. In het laatste onderdeel van hoofdstuk drie duiken we dieper in deze prima facie overtredingen. Onze conclusie is dat alleen Honduras (vanaf 2011) en Kameroen (vanaf 2015) de minimumkernverplichtingen afdoende hebben vastgelegd in hun onderwijswetgeving.

\section{Hoofdstuk 4 - Het testen van het recht op onderwijs}

In hoofdstuk 4 toetsten we of het recht op onderwijs (zoals gemeten in onze index) een effect heeft op onderwijsuitkomsten. We doen dit voor twee uitkomsten: het inschrijvingspercentage (het aantal kinderen van basisschoolleeftijd dat op een basisschool ingeschreven staat als percentage van het totaal aantal kinderen van die leeftijd) en het voltooiingspercentage (het aantal nieuwe leerlingen in de laatste klas van het basisonderwijs als percentage van het aantal kinderen dat op basis van hun leeftijd in die klas zouden moeten zitten).

Dit toetsen we in een statistisch regressiemodel. Dit stelt ons in staat om ook andere factoren ('variabelen') die invloed kunnen hebben op onderwijsuitkomsten mee te nemen. In deze studie gaat dat om het onderwijsbudget, hoe rijk een land is, of het land serieus omgaat met de rapportageplichten van verschillende internationale verdragen, wat de politieke oriëntatie van de regering is, hoe 
sterk de rechtstaat is, hoe de bevolking is opgebouwd, of het land het IVESCR geratificeerd heeft, en hoe sterk het maatschappelijk middenveld is. Daarnaast maken we gebruik maken van zogenaamde 'fixed-effects', waardoor ook met de invloed van tijd en structurele verschillen tussen landen rekening gehouden wordt.

De relatie tussen de wet en de uitkomsten is op drie verschillende manieren getoetst. Het eerste model toetste of er een direct effect was. De tweede toetste verschillende interacties tussen de wet en andere variabelen (het zou bijvoorbeeld kunnen dat er alleen een effect zichtbaar is als er ook voldoende geïnvesteerd wordt in onderwijs). De derde toetste of er ook een effect over tijd zichtbaar was en hoe lang dit aanhield. Uit het eerste model bleek geen statistisch significant verband tussen veranderingen in de wet en veranderingen in de onderwijsuitkomsten. Uit het tweede model bleek dat wetsveranderingen een significant positief effect hebben in landen met een zwakke rechtstaat en in landen met een laag onderwijsbudget (uitgedrukt in kosten per pupil). Onze hypothese is dat dit een prioriteringseffect is. Aangezien er in zulke landen niet genoeg capaciteit is om een wet volledig goed uit te voeren, is het waarschijnlijk dat met name die dingen uitgevoerd worden waar de wet nadruk op legt. Als de wet dus een sterke rechten-component heeft is het waarschijnlijker dat die aspecten worden uitgevoerd, wat resulteert in betere uitkomsten. Uit het derde model, ten slotte, bleek dat het veranderen van de wet een vertraagd effect heeft. $\mathrm{Na}$ ongeveer zeven tot negen jaar is er een statistisch significant positief effect zichtbaar, en dat blijft zo tot het einde van onze meting.

Als laatste hebben we een aantal landen onder de loep genomen om iets meer context bij de cijfers te creëren (op basis van bestaand onderzoek). Hieruit blijkt dat er in veel landen een 'reservoir' aan studenten is die al wel de basisschoolleeftijd bereikt hebben, maar nog niet naar school gaan door bepaalde barrières - bijvoorbeeld te hoge kosten, of een te beperkt aanbod. Als onderwijshervormingen deze barrières slechten dan schrijven zij zich massaal in, wat tot overvolle scholen leidt - en dus een afname van onderwijskwaliteit. Het kost het systeem een aantal jaar om dit te verwerken (bijvoorbeeld door extra scholen te bouwen, onderwijzers te trainen, en daarnaast natuurlijk dat deze groep door het schoolsysteem heen gaat). Dit zou het vertraagde effect kunnen verklaren. 


\section{Hoofdstuk 5 - Conclusies}

In het eerste hoofdstuk hebben we onszelf drie doelen gesteld:

1. Een juridisch kloppende meting van de wetgevende aspecten van mensenrechten;

2. De mogelijkheid om deze meting te gebruiken in een statistisch model om zo de relatie tussen wet en ontwikkeling te testen.

3. Dit te doen op een manier die toegankelijk is voor zowel juristen als sociale wetenschappers.

Met betrekking tot het eerste doel kwamen we er snel achter dat meten keuzes maken betekent. De uitkomst van elk van deze keuzes is dat je ook iets niet meet, waardoor de uitkomst van zo'n meetproces altijd onvolledige kennis oplevert. De drie voornaamste afwegingen in dit proces waren ten eerste die tussen flexibiliteit en vergelijkbaarheid, ten tweede tussen hoe nauwkeurig een meting is en hoe makkelijk te begrijpen, en ten derde tussen wat meetbaar is en wat eigenlijk zou moeten worden gemeten. Omdat we de meting wilden gebruiken in een statistisch model werd de eerste afweging beslecht in het voordeel van vergelijkbaarheid. Deze keuze leidde vervolgens tot de keuze voor het recht op basisonderwijs en de minimumkernverplichtingen om dat recht te conceptualiseren.

De tweede afweging was lastig, omdat wat als 'accuraat' of 'complex' wordt ervaren niet altijd hetzelfde is voor juristen of sociale wetenschappers. Ook bleek de gemakkelijk te begrijpen lijst van minimumkernverplichtingen nog heel wat extra keuzes te vereisen in het dataverzamelingsproces, waardoor er een aantal (te) complexe indicatoren tussen zitten.

Bij de derde afweging hebben we ons laten leiden door het juridische begrip van het recht op onderwijs, in plaats van meetbaarheid. Dit is in zoverre gelukt dat we een betrouwbare meting hebben van in hoeverre de minimumkernverplichtingen van het recht op onderwijs in de wet zijn vastgelegd. Hoewel dit ontegenzeggelijk een verbetering is van bestaande instrumenten schiet het toch te kort, doordat het alleen op de minimum kern focust, in plaats van de volledige reikwijdte van het recht op onderwijs. Dit probleem speelt trouwens breder; onze onderwijsuitkomsten (inschrijvings- en voltooiingspercentage) zeggen bijvoorbeeld niets over in hoeverre het onderwijs inclusief is, of van 
goede kwaliteit. Deze dissertatie laat zich dus het best lezen als een meting van de minimum kern van het recht op onderwijs en haar effect op de minimum uitkomsten van datzelfde recht.

Wanneer we de uitkomsten van dit onderzoek in een breder perspectief plaatsen vallen een aantal zaken op. Het eerste is dat de sterke toename van het aantal kinderen dat naar de basisschool gaat (en deze ook afmaakt) sterk toegenomen is de afgelopen dertig jaar. Helaas is de bescherming van het recht op onderwijs niet in dezelfde mate toegenomen, waardoor deze winst bijzonder gevoelig is voor economische, sociale, of politieke schokken - zoals een wereldwijde pandemie. Het tweede is dat ontwikkeling een proces van de lange adem is. In onze studie duurde het zeven tot negen jaar voordat er een meetbaar effect was van sterkere rechtsbescherming, en dan nog alleen op relatief simpele uitkomsten. We mogen aannemen dat het nog veel langer duurt voordat meer complexe uitkomsten (zoals een onderwijssysteem waarin het kind centraal staat, of waarin jongens en meisjes echt gelijke kansen hebben) zichtbaar zijn. Het is dus essentieel dat alle belanghebbenden weten dat ze aan zo' $n$ lang proces beginnen, en er genoeg middelen voor vrijmaken.

Misschien bent $\mathrm{u}$ wel bekend met het gedachte-experiment 'het schip van Theseus'. Door de jaren heen worden er telkens onderdelen vervangen, hetzij door slijtage, hetzij doordat er wat beters op de markt komt. Op welk moment in dat proces kun je zeggen: dit is het originele schip niet meer? Een terugkerend thema in deze dissertatie is dat er in het meetproces kennis verloren gaat. In de vertaling van wetteksten naar nummers, in het platstampen van nuanceverschillen om maar tot een vergelijking te komen, en in al die andere grote en kleine keuzes die gemaakt worden onderweg. De allerlaatste vraag die we onszelf dus moeten stellen is deze: wanneer in dit proces kun je niet meer spreken van een recht? En zit de meting waar we zoveel moeite in gestoken hebben vóór of ná dit punt? 